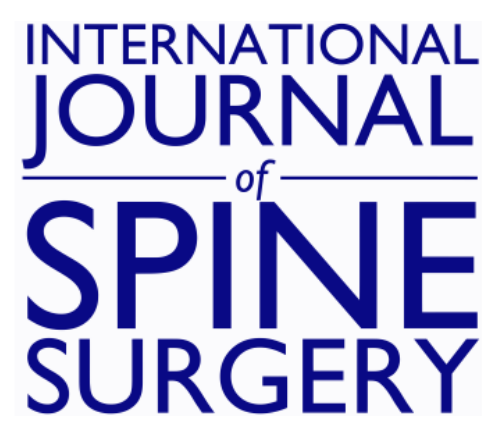

\title{
Clinical Outcomes of Cervical Hybrid Reconstructions: A Prospective Study
}

Matthew Scott-Young, Laurence McEntee, Evelyne Rathbone, Wayne Hing and David Nielsen

Int J Spine Surg 2020, 14 (s2) S57-S66

doi: https://doi.org/10.14444/7092

http://ijssurgery.com/content/14/s2/S57

This information is current as of April 26, 2023.

Email Alerts Receive free email-alerts when new articles cite this article. Sign up at:

http://ijssurgery.com/alerts

The International Journal of Spine Surgery

2397 Waterbury Circle, Suite 1,

Aurora, IL 60504, Phone: +1-630-375-1432 


\title{
Clinical Outcomes of Cervical Hybrid Reconstructions: A Prospective Study
}

\author{
MATTHEW SCOTT-YOUNG, MBBS, ${ }^{1,2}$ LAURENCE MCENTEE, MBCHB, BHB, ${ }^{1,2}$ EVELYNE RATHBONE, \\ MSC, CSTAT, ${ }^{2}$ WAYNE HING, PHD, MSC, OMT, DPHYS, ${ }^{2}$ DAVID NIELSEN, MBBS, BBIOMEDSC ${ }^{1}$ \\ ${ }^{I}$ Gold Coast Spine, Gold Coast, Queensland, Australia, ${ }^{2}$ Faculty of Health Science and Medicine, Bond University, Gold Coast, Queensland, Australia
}

\begin{abstract}
Background: The study design was a prospective clinical cohort study. The aim of this study was to assess the patient-reported outcome measures (PROMs), patient satisfaction, as well as complication and reoperation rate of cervical hybrid procedures for symptomatic cervical multilevel degenerative disc disease (MLDDD). Cervical total disc replacement (CTDR) has been shown to be safe and effective for the treatment of degenerative pathologies. However, there is minimal PROMs data on the outcomes of combined CTDR and anterior cervical decompression and fusion procedures, commonly referred to as cervical hybrid surgery.

Methods: Prospectively collected PROMs were analyzed from patients receiving cervical hybrid surgery for symptomatic cervical MLDDD. Between 2004 and 2016, data were collected preoperatively and postoperatively at 3, 6, and 12 months, then yearly thereafter. Patient reported outcome measures included patient satisfaction, visual analog score for neck and arm, and Neck Disability Index. Complication and reoperation rates were also assessed.

Results: A total of 151 patients ( 80 males, 71 females) who had a minimum of 12 months follow up were included. The mean age was 53 years (range $=24-81$ ), and median follow up was 2 years (range $=1-10$ ). The median number of levels treated was 3 , with $29.8 \%, 49.0 \%$, and $21.2 \%$ of patients having 2,3 , and 4 levels treated, respectively. The most common indication for surgery was multilevel cervical spondylotic radiculopathy $(52.8 \%)$, followed by combined cervical spondylotic radiculomyelopathy (16.7\%), axial neck pain (16\%), and cervical spondylotic myelopathy (13.9\%). Improvement in pain and disability scores were both clinically and statistically significant $(P<.001)$, and these improvements were sustained throughout the course of follow up. There was a $16 \%$ incidence of minor adverse events, and $3(1.9 \%)$ reoperations.

Conclusions: Cervical hybrid surgery for cervical MLDDD demonstrates favorable and sustained clinical outcomes at short-term to midterm follow up.

Level of Evidence: 4.

Clinical Relevance: Statistically and substantial clinical benefits can be achieved by cervical hybrid surgery, in the treatment of cervical pathologies including radiculopathy and myelopathy. The key principles is to follow strict indications, and to match technology with the pathology.
\end{abstract}

Special Issue-Cervical Spine

Keywords: artificial disc, arthroplasty, disc replacement, neck pain, degenerative disc disease, cervical hybrid reconstruction, cervical spine, motion preservation

\section{INTRODUCTION}

The prevalence of cervical multilevel degenerative disc disease (MLDDD) in the general adult population is relatively high, with as many as $5 \%$ of the population reporting symptoms attributable to their cervical degeneration. ${ }^{1}$ The presence of MLDDD in the cervical spine can result in a variety of clinical symptoms such as axial neck pain, unilateral or bilateral cervical spondylotic radiculopathy (CSR), cervical spondylotic myelopathy (CSM), or with a combination of these symptoms referred to as cervical spondylotic radiculomyelopathy (CSRM).
Symptomatic cervical MLDDD is a common presentation in spinal practice. While the majority of patients manage their symptoms with nonoperative measures, operative treatment in appropriate cases can positively impact an affected patient's function and quality of life. ${ }^{2,3}$ Anterior cervical decompression and fusion (ACDF) is the accepted surgical standard for the treatment of MLDDD in the cervical spine. There are many reports on the high rates of clinical success in relieving pain and neurological dysfunction with ACDF. ${ }^{4,5}$ However, authors also report increased biomechanical stress resulting in radiologic adjacent segment pathology 
(RASP) and subsequent clinical adjacent segment pathology (CASP). ${ }^{6}$ Pseudarthrosis may also be encountered, an effect that is increased in multilevel fusion. ${ }^{4,7}$ In addition, problems can arise related to graft source, such as donor morbidity or, in the case of allografts, ${ }^{8}$ the theoretical risk of disease transmission. ${ }^{9}$ The use of off-label products and bone extenders or enhancers in response to these issues creates further potential for adverse events and additional costs. ${ }^{10}$

Cervical total disc replacement (CTDR) preserves segment motion, allowing for load-sharing, and thereby a potential reduction of RASP and CASP. ${ }^{11,12}$ It avoids the bone graft-related complications and allows for a quicker recovery. The benefits and cost effectiveness of CTDR have been increasingly documented, while the disadvantages of traditional strategies such as multilevel ACDF are increasingly understood. ${ }^{13-19}$ The Food and Drug Administration (FDA) Approved Investigational Device Exemption (IDE) studies have been conducted and published. While the studies have provided strict inclusion and exclusion criteria in the United States (US on label), there are patients who are treated with CTDR both in the US and outside the US that do not follow this criteria strictly (US off label). The articles published outside the US on CTDR have slightly different indications and contraindications, thus creating ambiguity as to which pathology is suitable for CTDR. $^{20-23}$ Discussion continues as to the best treatment strategy in a patient with multilevel cervical pathology who is a candidate for multilevel CTDR, multilevel ACDF, or a hybrid construct with a combination of both CTDR and ACDF. ${ }^{24-27}$ Auerbach et $\mathrm{al}^{28}$ outlined contraindications to CTDR and retrospectively investigated 167 consecutive patients, reporting that $43 \%-47 \%$ of patients qualified for CTDR. Common contraindications to CTDR include osteoporosis, facet arthropathy, and advanced degenerative disc disease (DDD). In practice, contraindications and Medicare rebates often limit the feasibility of multilevel arthroplasty constructs. $^{28-31}$

Chin-See-Chong et $\mathrm{al}^{32}$ published the results of a Web-based survey sent to AO-Spine members internationally in which 387 members from 67 countries responded. The majority $(84.3 \%)$ used $\mathrm{ACDF}$ as the standard procedure, $47.8 \%$ occasionally performed CTDR, while $7.3 \%$ performed CTDR as the standard approach. When questioned about reasons for not performing CTDR, low evidence for benefits of CTDR over other surgical techniques $(33.2 \%)$ and costs $(29.6 \%)$ were noted. In addition, legal concerns and insurance coverage were also cited.

The benefit of cervical hybrid surgery is preservation of motion through the construct, while still offering appropriate treatment at levels contraindicated for arthroplasty. Motion preservation allows load sharing, which provides a more favorable biomechanical environment at adjacent segments compared with that afforded by fusion surgery, thereby reducing the compensatory hypermobility and peak stresses that would otherwise accelerate the processes of RASP and CASP. ${ }^{33-40}$ Currently, there are only limited reported studies on cervical hybrid surgery that tend to be short-term studies of small patient cohorts. ${ }^{41,42}$ The existing reports, and subsequent systemic reviews synthesizing those reports, demonstrate cervical hybrid surgery to have equivalent outcomes and functional recovery compared with multilevel ACDF, superior range of motion, and favorable improvements in Neck Disability Index (NDI). ${ }^{24,26,27,42-48}$

The objective of the current study is to document the prospective short-term to midterm outcomes of patients who underwent cervical hybrid surgery for multilevel CSR, CSM, and CSRM.

\section{MATERIALS AND METHODS}

This prospective clinical cohort study occurred between 2004 and 2016. Patients were consecutively enrolled from a 2-surgeon spinal practice, presenting with 2- to 4-level cervical MLDDD (including either axial pain, CSR, CSM, or CSRM), and who underwent cervical hybrid surgery. The clinical and patient outcomes of spinal surgery study (the study) was approved by the Bond University Human Research Ethics Committee (0000015881).

Patients were evaluated after a clinical history, physical examination, uniform radiological investigations, and a positive electromyography (EMG) to confirm the diagnosis. Radiological investigations included anterior-posterior/lateral-flexion/extension $(\mathrm{AP} / \mathrm{L} / \mathrm{F} / \mathrm{E}) \mathrm{x}$-rays, neutral and extension magnetic resonance imaging (MRI), discography (when indicated), and fine-cut computerized tomography (CT) scans (Figure 1).

Exclusion criteria for cervical hybrid surgery included osteoporosis, inflammatory disorders, deformity, instability, fractures, tumor, infections, and 

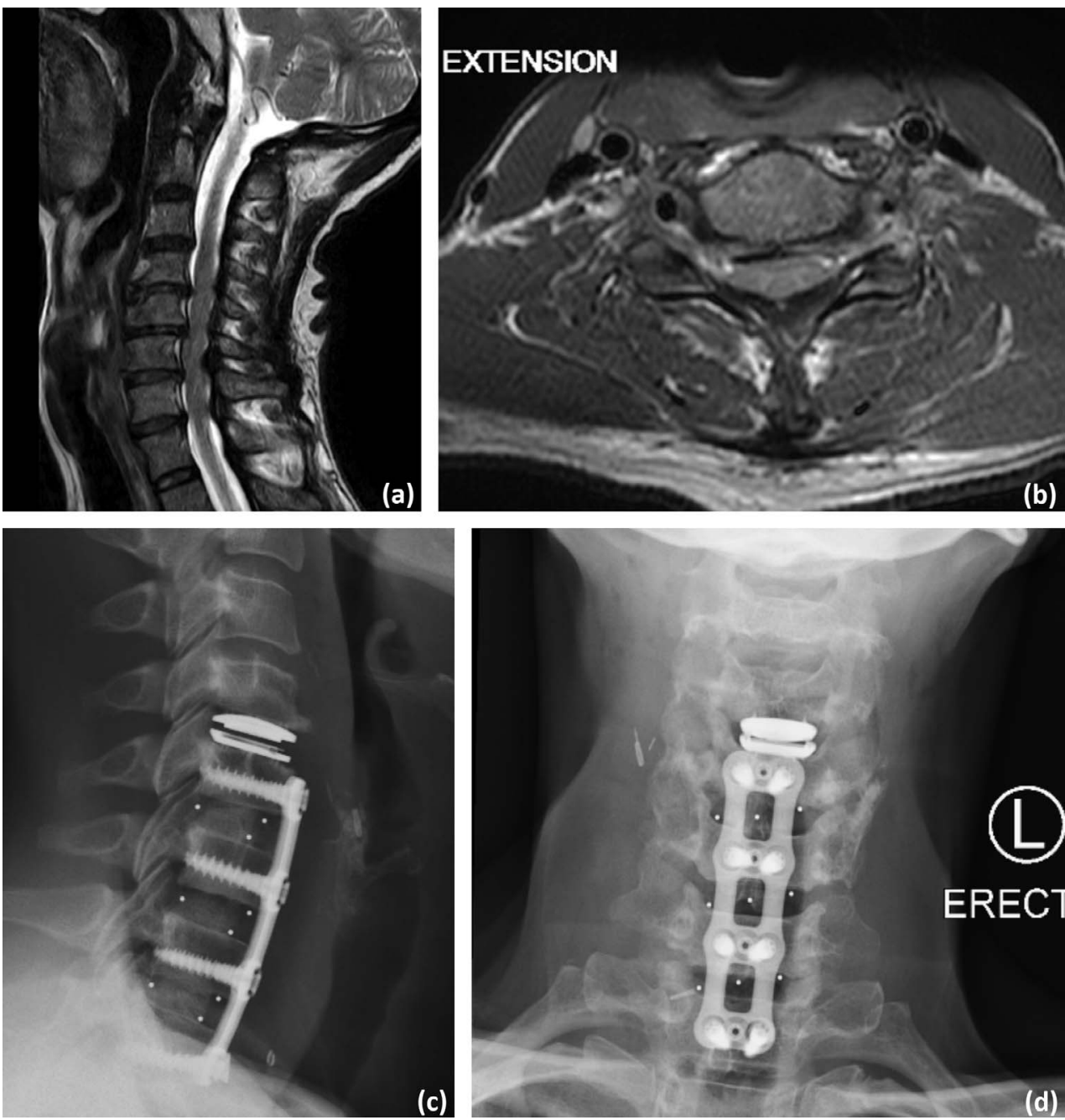

Figure 1. Preoperative magnetic resonance imaging: (a) sagittal and (b) axial, and postoperative radiographs: (c) lateral and (d) anterior-posterior images for a patient with cervical spondylotic radiculomyelopathy (CSRM) who subsequently underwent a 4-level cervical hybrid surgery.

overt psychosocial issues. Specific contraindications for the CTDR levels included significant facet arthropathy (Weishaupt et $\mathrm{al}^{49}$ classification $\geq$ grade 2), central and lateral recess stenosis, severe endplate abnormality, and complete or near complete (joint space $\leq 2 \mathrm{~mm}$ ) ankylosis. These segments were treated with ACDF. Regarding inclusion criteria for CTDR, essentially any symptomatic disc with normal bone density, normal endplate geometry, normal or grade 1 unilateral facet arthropathy, or neurocompressive pathology (bone or soft tissue) with correlating EMG were considered eligible. Specific inclusion and exclusion criteria for CTDR levels are listed in Table 1.

The surgical technique for cervical hybrid surgery followed a standard anterior cervical approach as described by Smith and Robinson. ${ }^{50}$ Postoperatively, patients mobilized without neck orthoses and underwent physiotherapy with instructions on
Table 1. Inclusion and exclusion criteria for levels receiving cervical total disc replacement (CTDR).

\begin{tabular}{l}
\hline Criteria \\
\hline Inclusion Criteria \\
$18-70$ years old \\
Pathology at $1-4$ levels (continuous/noncontinuous) \\
Radiculopathy/myelopathy (confirmed by electromyography) \\
Radiographic confirmation of neurocompressive pathology \\
Exclusion Criteria \\
Osteoporosis \\
Severe endplate abnormalities \\
Central and lateral recess stenosis secondary to bone compression \\
Inflammatory/metabolic disorders \\
Instability \\
Fracture \\
Tumors \\
Infection \\
Facet arthropathy (Weishaupt $\geq 3$ ) \\
Ankylosis or near ankylosis $(<2$ mm disc height) \\
Psychological issues \\
Noncompliance with study protocol \\
\hline
\end{tabular}


postural education, neural glides and stretches, and progressive range of motion exercises. Postoperative radiographic assessment was performed to assess the structural result, motion at the total disc replacement (TDR) segment, and union of the ACDF segments. The assessment included (AP/L/ $\mathrm{F} / \mathrm{E})$ radiographs at 3 months, repeated at 6 months, along with fine-cut CT scans to confirm the structural result.

Patient-reported outcome measures (PROMs), including visual analog score-neck (VAS-N, range $=0-100$ points), visual analog score-arm (VAS-A, range $=0-100$ points), and NDI (range $=0 \%-$ $100 \%$ ). Patient-reported outcome measures were collected preoperatively, then postoperatively at 3, 6, and 12 months, and annually thereafter. Patient satisfaction data collected were categorized as excellent, good, satisfactory, or poor. Complications and revision surgeries were also analyzed. The PROMS of patients undergoing revision/reoperation surgery were then reviewed separately from the grouped analysis, from the timepoint of their return to theater.

Statistical analysis was conducted in $\mathrm{R}$ version 3.5.3. The VAS for neck and arm pain and NDI continuous outcomes were analyzed as measured on a 100-point scale and as change from baseline (before surgery). The raw data were skewed and hence are presented as median interquartile range (IQR) for the multiple timepoints from 3 to 120 months. The change from baseline scores were normally distributed and were tested using paired $t$ tests up to 84 months, beyond which the sample size dropped to below 10. To account for multiplicity within each outcome, the mean difference was deemed to be statistically significant if $P<.0056$.

Graphical representations of the mean changes from baseline and 95\% confidence interval (CI) were plotted, along with the minimum clinically important difference (MCID) of 25 points for VAS$\mathrm{N}$ and VAS-A, and $15 \%$ NDI. The NDI outcomes were also compared with literature descriptions for substantial clinical benefit (SCB) threshold of $19 \%$. $^{51,52}$

\section{RESULTS}

In this study, 151 patients with cervical hybrid surgery were included: $53 \%(\mathrm{n}=80)$ male, $47 \%(\mathrm{n}=$ 71) female. The mean age at time of surgery was 53 years (range $=24-80$ ). The cohort had a median 2year follow up (range $=1-10$ years; Table 2 ). The
Table 2. Characteristics of 151 patients presenting for cervical hybrid surgery Data are presented as $n(\%)$, unless otherwise indicated.

\begin{tabular}{lc}
\hline Characteristic & $\boldsymbol{n}(\mathbf{\%})$ \\
\hline Gender & \\
Male & $80(53.0)$ \\
Female & $71(47.0)$ \\
Age (y) at time of surgery & \\
Mean (SD) & $53.0(10.4)$ \\
Range & $24.1-81.0$ \\
$<35$ & $7(4.6)$ \\
$35-45$ & $27(17.9)$ \\
$>45$ & $117(77.5)$ \\
Latest postoperative follow up ${ }^{\text {a }}$ (months) & $37(24.5)$ \\
12 & $40(26.5)$ \\
24 & $29(19.2)$ \\
36 & $24(15.9)$ \\
48 & $21(13.9)$ \\
$>60$ & \\
Diagnostic breakdown for multilevel cervical hybrid cases & $79(52.3)$ \\
Cervical spondylotic radiculopathy (CSR) & $21(13.9)$ \\
Cervical spondylotic myelopathy (CSM) & $26(17.2)$ \\
Cervical spondylotic radiculomyelopathy (CSRM) & $25(16.6)$ \\
Other (axial neck pain) & \\
\hline
\end{tabular}

${ }^{\text {a }}$ Postoperative timepoints were captured at 3, 6, and 12 months postoperation and then annually thereafter in accordance with inclusion and exclusion criteria. Latest follow up at time of data analysis is presented as months after surgery, with numbers and relative proportions of the cohort listed.

median number of levels treated was 3, with $29.8 \%$, $49.0 \%$, and $21.2 \%$ of patients having 2,3 , and 4 levels treated, respectively. The most common indication for surgery was multilevel CSR in $52.8 \%$ of patients. Regarding funding, 5 patients $(3.3 \%)$ were in receipt of compensation, while 1 patient was a veteran. The remaining patients were funded by their respective private health insurance funds.

A total of 167 CTDR prostheses were used. Total disc replacement was performed at $\mathrm{C} 3-4(\mathrm{n}=36$, $21.6 \%), C 4-5(n=78,46.7 \%), C 5-6(n=44,26.3 \%)$, and C6-7 $(\mathrm{n}=9,5.4 \%)$. Anterior cervical decompression and fusion was performed at 278 levels, predominantly at C6-7 $(\mathrm{n}=120,43.2 \%)$ and C5-6 (n $=107,38.5 \%)$. The most common combination was a 3-level cervical hybrid, with CTDR at C4-5 and $\mathrm{ACDF}$ at $\mathrm{C} 5-6$ and $\mathrm{C6}-7$. The second most common combination was a 2-level hybrid, with CTDR at C56 and ACDF at C6-7 (Table 3).

Tables 4 and 5 show the summary statistics for the VAS and NDI outcomes, respectively. Clinically and statistically significant improvements were seen in the patient cohort for VAS-A and VAS-N up to 60 months, when the sample size was sufficiently large. Clinical significance was achieved at 84 months for both VAS outcomes as the mean improvements were above the MCID of 25 (Figures 2 and 3 ). Both clinically and statistically significant improvements were achieved in NDI scores over an 
Table 3. Summary of operations performed.

\begin{tabular}{lc}
\hline Cervical Hybrid Surgery Details & $\boldsymbol{n}(\mathbf{\%})$ \\
\hline Operation $^{\mathrm{a}}$ & \\
1-Level CTDR + 1-Level ACDF & $45(29.8)$ \\
1-Level CTDR + 2-Level ACDF & $67(44.4)$ \\
1-Level CTDR + 3-Level ACDF & $26(17.2)$ \\
2-Level CTDR + 1-Level ACDF & $7(4.6)$ \\
2-Level CTDR + 2-Level ACDF & $3(2.0)$ \\
3-Level CTDR + 1-Level ACDF & $3(2.0)$ \\
Levels treated & \\
CTDR & \\
C2-3 & $0(0.0)$ \\
C3-4 & $36(21.6)$ \\
C4-5 & $78(46.7)$ \\
C5-6 & $44(26.3)$ \\
C6-7 & $9(5.4)$ \\
C7-T1 & $0(0.0)$ \\
Total & 167 \\
ACDF & \\
C2-3 & $1(0.4)$ \\
C3-4 & $6(2.2)$ \\
C4-5 & $37(13.3)$ \\
C5-6 & $107(38.5)$ \\
C6-7 & $120(43.2)$ \\
C7-T1 & $7(2.5)$ \\
Total & 278 \\
&
\end{tabular}

Abbreviations: ACDF, anterior cervical decompression and fusion; CTDR, cervical total disc replacement.

${ }^{\mathrm{a}}$ Type of CTDR and ACDF prosthesis used was dependent on surgeon preference and availability at time of procedure.

${ }^{\mathrm{b}}$ CTDR was performed via anterior approach. Patients received either single-level or multilevel CTDR depending upon respective diagnosis.

${ }^{\mathrm{c}} \mathrm{ACDF}$ was performed by anterior approach with a cage/bone graft and plate

fixation construct.

84-month period (Figure 4). The MCID between preoperative and final follow-up time periods was assessed using thresholds defined in the literature. $^{51,52}$ Irrespective of diagnosis, the proportion of individuals who reached MCID thresholds were $72.2 \%$ and $75.5 \%$ for VAS-N and VAS-A, respectively (change $\geq 25$ points). Furthermore, $81.5 \%$ in NDI achieved both MCID and SCB thresholds (change $\geq 15 \%$ and $\geq 19 \%$, respectively). These outcomes were sustained until 10 years after surgery. Maximal improvements in symptom reduction for VAS-N and VAS-A were reached by 12 months and maintained through the course of follow up. Patient satisfaction was excellent/good in more than $80 \%$ of patients at most timepoints to 8-year follow up (Figure 5 and Table 6). The patients with the longest follow up, up to 10 years, did not show a significant decay in outcomes. However, it should be noted that the number of patients available for long-term assessment was too small to draw definitive conclusions from.

The effect of the arthroplasty level and construct type was unclear, with no significant difference in outcomes noted between the combinations. ${ }^{36}$ However, this likely reflects the low numbers in the different treatment groups. As noted, the most common construct was a 3-level cervical hybrid, with a 1-level CTDR cranially, and ACDF at the 2 caudal levels.

There was a $16 \%$ incidence of minor adverse events (swelling, transient dysphagia, suture granuloma). There were $3(1.9 \%)$ reoperations, 2 operations for drainage of hematoma, and 1 operation for removal of a TDR prosthesis, with conversion to an ACDF. The revision was performed for early mechanical failure at the 6 months' follow up. There was no additional surgery for RASP/CASP.

\section{DISCUSSION}

This prospective cohort of cervical hybrid surgery patients demonstrates clinically and statistically significant reductions in both pain and disability and adds to the current literature on cervical motion preservation. The theory of motion preservation in the cervical spine has been extensively studied in the last decade. Hybrid strategies have been associated with achieving in vivo cervical motion in patients, allowing adjacent segment kinematics that are not significantly different to preoperative physiological motion. ${ }^{33,34,53,54,55}$ Concurrently, literature continues to emerge addressing the long-term outcomes and complications of multilevel ACDF. Buttermann ${ }^{56}$ reported long-term follow up of multilevel ACDF patients and found a $21 \%$ rate of reoperation for adjacent motion segment disease and a $10 \%$ rate of pseudarthrosis. Given the equipoise with the single-level FDA-IDE studies on clinical outcomes, the addition of CTDR to a multilevel construct would probably not diminish the clinical outcome, provided inclusion and exclusion criteria are adhered to. It is distinctly possible that there may be reduced RASP and CASP, less pseudoarthrosis, less revision procedures, and therefore improved clinical outcome in cervical hybrid patients.

The prospect of reduced RASP and CASP, in combination with promising early outcomes, has led to a gradual increase in the number of single-level CTDR procedures being performed. This has evolved into multiple-level constructs for MLDDD being reported in the literature with promising results. ${ }^{56}$ Given that cervical DDD often involves multilevel pathology, it is important to have a reconstructive strategy that addresses the symptomatic levels, while achieving satisfactory functional outcomes and minimizing the risk of revision and reoperation. Zhang et $\mathrm{al}^{46}$ investigated the outcomes and reliability of cervical hybrid surgery versus 
Table 4. Summary statistics for visual analog scale (VAS) outcomes for neck (VAS-N) and arm (VAS-A) pain over time.

\begin{tabular}{|c|c|c|c|c|c|c|c|}
\hline \multirow[b]{2}{*}{ Time Postsurgery, mo } & \multicolumn{3}{|c|}{ VAS $^{\text {a }}$ Outcome } & \multicolumn{4}{|c|}{ Change From Baseline } \\
\hline & $n$ & Median & Interquartile Range & $n$ & Mean Difference ${ }^{b}$ & 95\% Confidence Interval & $P$ Value $^{\mathrm{c}}$ \\
\hline \multicolumn{8}{|l|}{ VAS-N } \\
\hline 0 baseline & 151 & 75.0 & $61.0-87.0$ & & & & \\
\hline 3 & 144 & 23.0 & $8.8-58.0$ & 144 & 37.9 & $32.7-43.0$ & $<.001^{\mathrm{d}}$ \\
\hline 6 & 142 & 21.5 & $6.0-46.0$ & 142 & 41.6 & $36.2-47.0$ & $<.001^{\mathrm{d}}$ \\
\hline 12 & 135 & 15.0 & $5.0-38.0$ & 135 & 44.3 & $38.4-50.1$ & $<.001^{\mathrm{d}}$ \\
\hline 24 & 92 & 25.5 & $4.0-52.5$ & 92 & 39.1 & $32.1-46.1$ & $<.001^{\mathrm{d}}$ \\
\hline 36 & 58 & 18.0 & $4.0-38.0$ & 58 & 45.9 & $37.4-54.4$ & $<.001^{\mathrm{d}}$ \\
\hline 48 & 37 & 15.0 & $5.0-48.0$ & 37 & 40.9 & $30.4-51.4$ & $<.001^{\mathrm{d}}$ \\
\hline 60 & 19 & 18.0 & $3.5-35.0$ & 19 & 46.9 & $30.7-63.1$ & $<.001^{\mathrm{d}}$ \\
\hline 72 & 9 & 25.0 & $10.0-62.0$ & 10 & 24.8 & $-7.3-56.8$ & .112 \\
\hline 84 & 10 & 20.5 & $6.8-42.3$ & 10 & 35.9 & $12.0-59.8$ & .008 \\
\hline 96 & 7 & 35.0 & $18.5-75.0$ & $7^{e}$ & & & \\
\hline 108 & 4 & 54.0 & $28.3-75.0$ & $4^{\mathrm{e}}$ & & & \\
\hline 120 & 4 & 32.0 & $7.8-58.8$ & $4^{e}$ & & & \\
\hline \multicolumn{8}{|l|}{ VAS-A } \\
\hline 0 baseline & 151 & 47.0 & $9.0-70.5$ & & & & \\
\hline 3 & 144 & 4.0 & $0.0-20.0$ & 144 & 26.5 & $20.4-32.7$ & $<.001^{\mathrm{d}}$ \\
\hline 6 & 142 & 3.0 & $0.0-14.8$ & 142 & 26.5 & $20.7-32.4$ & $<.001^{\mathrm{d}}$ \\
\hline 12 & 134 & 2.0 & $0.0-13.0$ & 134 & 31.6 & $25.9-37.3$ & $<.001^{\mathrm{d}}$ \\
\hline 24 & 93 & 5.0 & $0.0-31.0$ & 93 & 25.1 & $17.9-32.3$ & $<.001^{\mathrm{d}}$ \\
\hline 36 & 58 & 3.0 & $0.0-18.8$ & 58 & 29.7 & $19.4-40.0$ & $<.001^{\mathrm{d}}$ \\
\hline 48 & 38 & 3.5 & $1.0-16.5$ & 38 & 25.7 & $13.5-38.0$ & $<.001^{\mathrm{d}}$ \\
\hline 60 & 18 & 3.0 & $0.3-16.0$ & 18 & 29.2 & $14.0-44.5$ & $<.001^{\mathrm{d}}$ \\
\hline 72 & 9 & 5.0 & $0.0-26.0$ & 10 & 12.7 & $-14.2-39.5$ & .308 \\
\hline 84 & 10 & 1.0 & $0.3-6.8$ & 10 & 31.4 & $5.2-57.6$ & .024 \\
\hline 96 & 7 & 35.0 & $4.5-39.0$ & $7^{e}$ & & & \\
\hline 108 & 4 & 27.0 & $20.3-43.5$ & $4^{\mathrm{e}}$ & & & \\
\hline 120 & 4 & 30.0 & $21.0-33.8$ & $4^{e}$ & & & \\
\hline
\end{tabular}

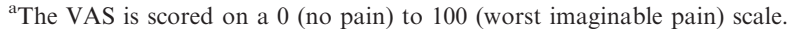

${ }^{\mathrm{b}}$ A positive mean difference indicates an improvement or reduction in VAS score from baseline (prior to surgery).

${ }^{c}$ The $P$ value is the result of the paired $t$-test. Significance is achieved when $P<0.0056$ using Bonferroni correction within each type of outcome.

${ }^{\mathrm{d}}$ Statistically significant at the 0.0056 level.

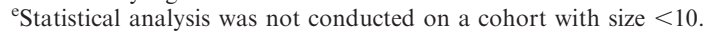

ACDF for the treatment of MLDDD in the cervical spine. Their meta-analysis indicates that, compared with ACDF alone, cervical hybrid surgery provides equivalent outcomes in PROMs. Furthermore, the addition of motion preservation of the cervical range of motion affords a concordant reduction in adjacent segment disease. However, it is noted that there are currently no randomized controlled trials (RCTs) comparing cervical hybrid surgery with other strategies. There is also heterogeneity between existing studies with regard to indications for surgery and differences in implants used.

Table 5. Summary statistics for Neck Disability Index (NDI) outcome over time.

\begin{tabular}{|c|c|c|c|c|c|c|c|}
\hline \multirow[b]{2}{*}{ Time Postsurgery, mo } & \multicolumn{3}{|c|}{ NDI $^{\mathrm{a}}$ Outcome } & \multicolumn{4}{|c|}{ Change From Baseline } \\
\hline & $n$ & Median & Interquartile Range & $n$ & Mean Difference ${ }^{b}$ & 95\% Confidence Interval & $P$ Value \\
\hline 0 baseline & 151 & 48.0 & $36.0-56.0$ & & & & \\
\hline 3 & 145 & 20.0 & $10.0-32.0$ & 145 & 24.0 & $21.3-26.8$ & $<.001$ \\
\hline 6 & 140 & 20.0 & $9.5-30.5$ & 140 & 24.3 & $21.3-27.4$ & $<.001$ \\
\hline 12 & 135 & 16.0 & $8.0-26.0$ & 135 & 25.5 & $22.3-28.6$ & $<.001$ \\
\hline 24 & 92 & 18.0 & $9.5-34.5$ & 92 & 24.1 & $19.9-28.3$ & $<.001$ \\
\hline 36 & 59 & 20.0 & $6.5-29.0$ & 59 & 25.2 & $20.8-29.6$ & $<.001$ \\
\hline 48 & 37 & 16.0 & $12.0-30.0$ & 37 & 23.2 & $17.7-28.7$ & $<.001$ \\
\hline 60 & 18 & 18.0 & $12.0-27.5$ & 18 & 24.6 & $18.5-30.6$ & $<.001$ \\
\hline 72 & 10 & 17.0 & $7.0-24.5$ & 10 & 29.7 & $18.9-40.5$ & $<.001$ \\
\hline 84 & 10 & 19.0 & $5.8-25.0$ & 10 & 30.5 & $21.3-39.7$ & $<.001$ \\
\hline 96 & 7 & 18.0 & $9.0-42.0$ & $7^{d}$ & - & - & - \\
\hline 108 & 4 & 35.0 & $16.5-50.0$ & $4^{\mathrm{d}}$ & - & - & - \\
\hline 120 & 4 & 43.0 & $20.0-60.0$ & $4^{\mathrm{d}}$ & - & - & - \\
\hline
\end{tabular}

${ }^{a}$ The NDI is scored on a 0 (none) to 100 (worst) disability.

${ }^{\mathrm{b}} \mathrm{A}$ positive mean difference indicates an improvement or reduction in NDI from baseline (before surgery).

${ }^{\mathrm{c}}$ The $P$ value is the result of the paired $t$ test. Significance is achieved when $P<.0056$ using Bonferroni correction within each type of outcome. All differences from baseline were statistically significant.

${ }^{\mathrm{d}}$ Statistical analysis was not conducted on a cohort with size $<10$. 


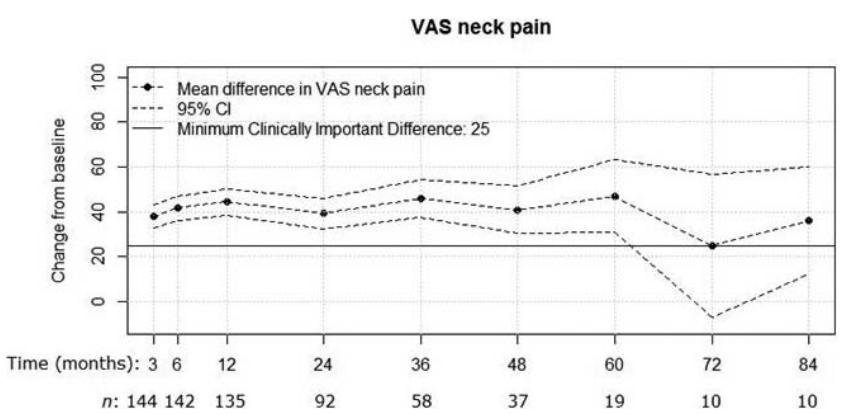

Figures 2. Mean improvement in visual analog scale-neck (VAS-N) score after surgery was statistically significant $(P<.001)$ up to 60 months, when sample size was sufficient, and clinically significant (MCID $\geq 25)$ at most timepoints.

It is important to discuss the concept of asymptomatic spinal cord compression (ASCC) and radiculopathy. This is a new concept based on quantitative MRI and quantitative EMG and has currently been proposed to supersede the specificity of the clinical examination to detect early pathological changes in the cord or nerve roots. Martin et $\mathrm{al}^{57}$ suggest that homeostatic mechanisms of neuroplasticity and behavioral adaption help to minimize early symptoms. The proportion of the cohort in this study that reached MCID was $72.2 \%$ for VAS$\mathrm{N}$ and $75.5 \%$ VAS-A. Noteworthy is the fact that the cohort of patients with chronic neck pain in our study had ASCC or radiculopathy diagnosed through quantitative electromyography (QEMG). The comparatively lower proportion of patients achieving MCID for VAS-N compared with VAS-A was not unexpected, as the indication for many of the patients was predominantly a clinical picture of CSR and CSM over axial neck pain. Many patients $(81.5 \%)$ improved by at least $20 \%$ for NDI, which achieved thresholds for both MCID and SCB. ${ }^{51}$ The results of our cohort support the limited number of midterm papers and recently published meta-anal-

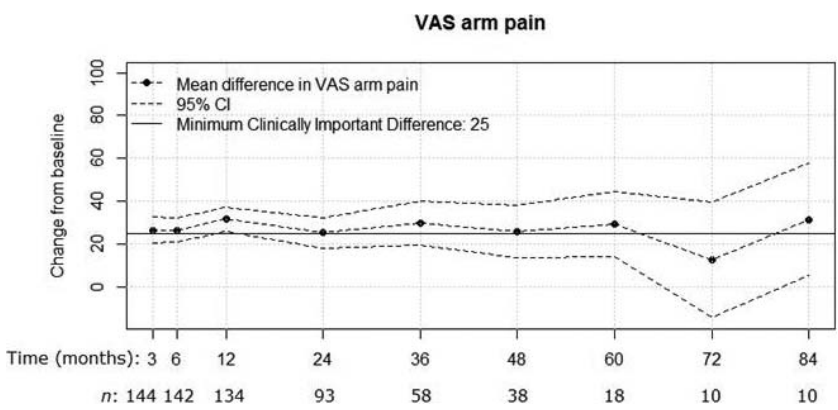

Figure 3. Mean improvement in visual analog scale-arm (VAS-A) pain score after surgery was statistically significant $(P<.001)$ up to 60 months, when sample size was sufficient, and clinically significant (MCID $\geq 25$ ) at most timepoints.

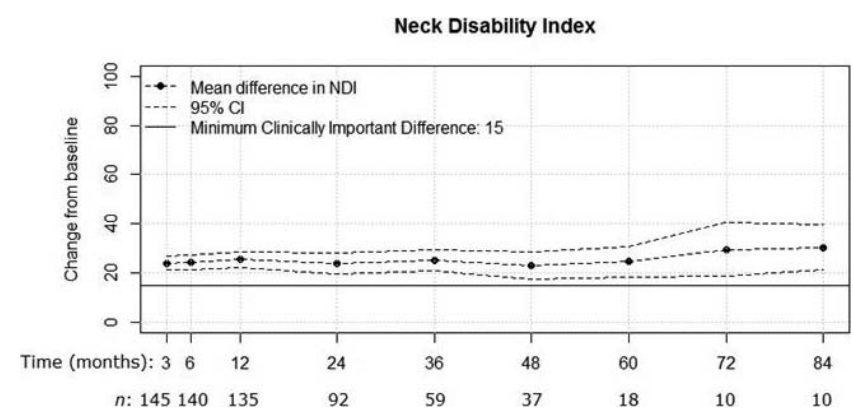

Figure 4. Mean improvement in Neck Disability Index (NDI) was statistically ( $P$ $<.001)$ and clinically significant (MCID $\geq 15$ ) over the 84-month period after surgery.

yses that report the functional outcomes to be at least equivalent to other strategies. ${ }^{41,42,46,47,58}$

The anterior approach allows for a well-established surgical strategy to treat cervical spine pathology. The complication rate was low in this group despite multiple levels being addressed. Meticulous surgical technique and knowledge of potential procedural and postoperative complications is essential. The combined revision/reoperation rate was 1.9\%. Buttermann $\mathrm{at}^{59} 5$ years found equivalent clinical outcomes, with a trend to lower pseudarthrosis and reoperation rates, in a cervical hybrid surgery cohort ( $8 \%$ ) when compared with a multilevel ACDF cohort (12\%).

While this current study has robustly collected data with consistent methodology, there are limitations to be acknowledged. It is important to understand that the low number of patients with longer-term data limits the ability to draw conclusions on the long-term performance of cervical hybrid surgery. The data in this cohort have not been considered in terms of deformity parameters, and automated alignment measurement was not available at the initiation of data collection. Cervical pathology, vertebral morphology, and spinal subtype vary between individual patients with the

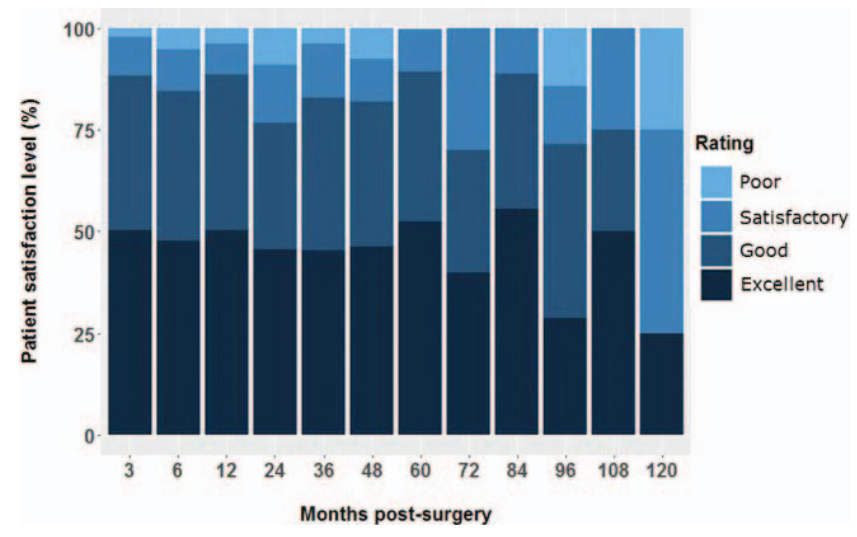

Figure 5. Patient satisfaction scores over time. 
Table 6. Summary statistics for patient satisfaction scores (excellent/good) ${ }^{a}$ over time.

\begin{tabular}{lcc}
\hline Time Postsurgery, mo & Total, $\boldsymbol{n}$ & Excellent/Good, $\boldsymbol{n}(\%)$ \\
\hline 3 & 137 & $121(88.3)$ \\
6 & 136 & $115(84.6)$ \\
12 & 133 & $118(88.7)$ \\
24 & 90 & $69(76.7)$ \\
36 & 53 & $44(83.0)$ \\
48 & 39 & $32(82.1)$ \\
60 & 19 & $17(89.5)$ \\
72 & 10 & $7(70.0)$ \\
84 & 9 & $8(88.9)$ \\
96 & 7 & $5(71.4)$ \\
108 & 4 & $3(75.0)$ \\
120 & 4 & $3(75.0)$ \\
\hline
\end{tabular}

${ }^{\mathrm{a}}$ Patients were asked to rate their satisfaction with the operation as excellent (1), good (2), satisfactory (3), or poor (4) on postoperative questionnaires.

prospect of affecting segmental motion and outcomes. ${ }^{54}$ Cervical alignment parameters and the relative performance of arthroplasty at different levels are only recently attracting attention. There is the yet unproven suggestion that different combinations of cervical hybrid surgery perform differently at different levels, with different spine subtypes and lordosis distribution. The authors suggest a commitment to consistent measurement of alignment and subtype of spine classification. Recently, a consensus has been reached on parameters for cervical deformity. ${ }^{60}$ This parallels the experience in the lumbar spine, where our institution has recently introduced automated alignment measurement tools, which are routinely used in planning reconstructions and verifying the postoperative erect alignment. Finally, the heterogeneity in patient clinical syndromes and surgical indications may have affected the results of the different outcomes measured.

The most important principles underpinning clinically successful cervical hybrid surgery are to accurately identify the symptomatic levels and to match the technology with the patient's pathology at each level. Currently, spinal implant manufacturers have a one-type-fits-all concept irrespective of the level treated or the pathological status at the symptomatic level. An important consideration for the future is to thoroughly review implant design and review the biomechanics and kinematics of each motion segment with a view to the creation of a level and/or pathology specific implant design.

\section{CONCLUSIONS}

This large prospective cohort demonstrates clinically and statistically improved midterm clinical outcomes with cervical hybrid surgery in suitable candidates with multilevel cervical pathology. The study demonstrates cervical hybrid surgery to be a safe and efficacious strategy, with comparatively low complication rates. Further reporting of longterm results of cervical hybrid surgery is important for understanding the potential for decay in these midterm outcomes. Ideally, level 1 evidence from an RCT comparing cervical hybrid surgery with either or both multilevel CTDR and ACDF would be desirable.

\section{REFERENCES}

1. Côté P, Cassidy DJ, Carroll LJ. The annual incidence and course of neck pain in the general population: a populationbased cohort study. Pain. 2004;112(3):267-273.

2. Anderson PA, Puschak TJ, Sasso RC. Comparison of short-term SF-36 results between total joint arthroplasty and cervical spine decompression and fusion or arthroplasty. Spine. 2009;34(2):176-183.

3. King JT Jr, McGinnis KA, Roberts MS. Quality of life assessment with the medical outcomes study short form-36 among patients with cervical spondylotic myelopathy. Neurosurgery. 2003;52(1):113-121. doi:10.1227/0006123-20030100000014

4. Bohlman HH, Emery SE, Goodfellow DB, Jones PK. Robinson anterior cervical discectomy and arthrodesis for cervical radiculopathy. Long-term follow-up of one hundred and twentytwo patients. J Bone Joint Surg Am. 1993;75(9):11298-11307.

5. Goffin J, Geusens E, Vantomme N, et al. Long-term follow-up after interbody fusion of the cervical spine. $J$ Spinal Disord Tech. 2004;17(2):79-85.

6. Hilibrand AS, Carlson GD, Palumbo MA, Jones PK, Bohlman HH. Radiculopathy and myelopathy at segments adjacent to the site of a previous anterior cervical arthrodesis. $J$ Bone Joint Surg Am. 1999;81(4):519-528.

7. Brodke DS, Zdeblick TA. Modified Smith-Robinson procedure for anterior cervical discectomy and fusion. Spine. 1992;17(10 Suppl):s427-s430.

8. Brown CA, Eismont FJ. Complications in spinal fusion. Orthop Clin North Am. 1998;29(4):679-699.

9. Mroz TE, Joyce MJ, Lieberman IH, Steinmetz MP, Benzel EC, Wang JC. The use of allograft bone in spine surgery: is it safe? Spine J. 2009;9(4):303-308.

10. Gupta A, Kukkar N, Sharif K, Main BJ, Albers CE, ElAmin Iii SF. Bone graft substitutes for spine fusion: a brief review. World J Orthop. 2015;6(6):449-456.

11. DiAngelo DJ, Robertson JT, Metcalf NH, McVay BJ, Davis RC. Biomechanical testing of an artificial cervical joint and an anterior cervical plate. J Spinal Disord Tech. 2003;16(4):314-323.

12. Wigfield C, Gill S, Nelson R, Langdon I, Metcalf N, Robertson J. Influence of an artificial cervical joint compared with fusion on adjacent-level motion in the treatment of degenerative cervical disc disease. J Neurosurg. 2002;96(1 Suppl):17-21.

13. Ament JD, Yang Z, Nunley P, Stone MB, Kim KD. Cost-effectiveness of cervical total disc replacement vs fusion 
for the treatment of 2-level symptomatic degenerative disc disease. JAMA Surg. 2014;149(12):1231-1239.

14. Ament JD, Yang Z, Chen Y, Green RS, Kim KD. A novel quality-of-life utility index in patients with multilevel cervical degenerative disc disease: comparison of anterior cervical discectomy and fusion with total disc replacement. Spine (Phila Pa 1976). 2015;40(14):1072-1078. doi:10.1001/ja masurg.2014.716

15. Radcliff K, Lerner J, Yang C, Bernard T, Zigler JE. Seven-year cost-effectiveness of ProDisc-C total disc replacement: results from investigational device exemption and postapproval studies. J Neurosurg Spine. 2016;24(5):760-768.

16. Laratta JL, Shillingford JN, Saifi C, Riew KD. Cervical disc arthroplasty: a comprehensive review of single-level, multilevel, and hybrid procedures. Global Spine J. 2018;8(1):78-83. doi:10.1177/2192568217701095

17. McAnany SJ, Merrill RK, Brochin RL, Overley SC, Kim JS, Qureshi SA. Comparing the 5-year health state utility value of cervical disc replacement and anterior cervical discectomy and fusion. Global Spine J. 2018;8(1):6-10.

18. Zhu Y, Zhang B, Liu H, Wu Y, Zhu Q. Cervical disc arthroplasty versus anterior cervical discectomy and fusion for incidence of symptomatic adjacent segment disease: a metaanalysis of prospective randomized controlled trials. Spine (Phila Pa 1976). 2016;41(19):1493-1502. doi:10.1097/BRS. 0000000000001537

19. Zou S, Gao J, Xu B, Lu X, Han Y, Meng H. Anterior cervical discectomy and fusion (ACDF) versus cervical disc arthroplasty (CDA) for two contiguous levels cervical disc degenerative disease: a meta-analysis of randomized controlled trials. Eur Spine J. 2017;26(4): 985-997.

20. McAfee PC, Reah C, Gilder K, Eisermann L, Cunningham B. A meta-analysis of comparative outcomes following cervical arthroplasty or anterior cervical fusion. Spine ( Phil Pa 1976). 2012;37(11):943-952.

21. Murrey D, Janssen M, Delamarter R, et al. Results of the prospective, randomized, controlled multicenter Food and Drug Administration investigational device exemption study of the ProDisc-C total disc replacement versus anterior discectomy and fusion for the treatment of 1-level symptomatic cervical disc disease. Spine J. 2009;9(4):275-286.

22. Mummaneni PV, Burkus JK, Haid RW, Traynelis VC, Zdeblick TA. Clinical and radiographic analysis of cervical disc arthroplasty compared with allograft fusion: a randomized controlled clinical trial. J Neurosurg Spine. 2007;6(3):198-209.

23. Heller JG, Sasso RC, Papadopoulos SM, et al. Comparison of BRYAN cervical disc arthroplasty with anterior cervical decompression and fusion: clinical and radiographic results of a randomized, controlled, clinical trial. Spine (Phil Pa 1976). 2009;34(2):101-107.

24. Ding F, Jia Z, Wu Y, et al. Fusion-nonfusion hybrid construct versus anterior cervical hybrid decompression and fusion: a comparative study for 3-level cervical degenerative disc diseases. Spine J. 2014;39(23):1934-1942. doi:10.1097/BRS. 0000000000000588

25. Cardoso MJ, Mendelsohn A, Rosner MK. Cervical hybrid arthroplasty with 2 unique fusion techniques. $J$ Neurosurg Spine. 2011;15(1):48-54. doi:10.3171/2011.3.SPINE10385

26. Kang L, Lin D, Ding Z, Liang B, Lian K. Artificial disk replacement combined with midlevel ACDF versus multilevel fusion for cervical disk disease involving 3 levels. Orthopedics. 2013;36(1):e88-94. doi:10.3928/01477447-20121217-24

27. Lu VM, Zhang L, Scherman DB, et al. Treating multilevel cervical disc disease with hybrid surgery compared to anterior cervical discectomy and fusion: a systematic review and meta-analysis. Eur Spine J. 2017;26(2):546-557. doi:10.1007/ s00586-016-4791-y

28. Auerbach JD, Jones KJ, Fras CI, Balderston JR, Rushton SA, Chin KR. The prevalence of indications and contraindications to cervical total disc replacement. Spine J. 2008;8(5):711-716.

29. Phillips FM, Tzermiadianos MN, Voronov LI, et al. Effect of two-level total disc replacement on cervical spine kinematics. Spine (Phila Pa 1976). 2009;34(22):794-799.

30. Dong L, Xu Z, Chen X, et al. The change of adjacent segment after cervical disc arthroplasty compared with anterior cervical discectomy and fusion: a meta-analysis of randomized controlled trials. Spine J. 2017;17(10):1549-1558.

31. Liao Z, Fogel GR, Pu T, Gu H, Liu W. Biomechanics of hybrid anterior cervical fusion and artificial disc replacement in 3-level constructs: an in vitro investigation. Med Sci Monit. 2015;21:3348-3355.

32. Chin-See-Chong TC, Gadjradj PS, Boelen RJ, Harhangi BS. Current practice of cervical disc arthroplasty: a survey among 383 AOSpine International members. Neurosurg Focus. 2017;42(2):E8.

33. Zhong Z-M, Zhu S-Y, Zhuang J-S, Wu Q, Chen J-T. Reoperation after cervical disc arthroplasty versus anterior cervical discectomy and fusion: a meta-analysis. Clin Orthop Relat Res. 2016;474(5):1307-1316.

34. Patwardhan AG, Havey RM, Khayatzadeh S, et al. Postural consequences of cervical sagittal imbalance: a novel laboratory model. Spine (Phila Pa 1976). 2015;40(11):783-792.

35. Gandhi AA, Grosland NM, Kallemeyn NA, Kode S, Fredericks DC, Smucker JD. Biomechanical analysis of the cervical spine following disc degeneration, disc fusion, and disc replacement: a finite element study. Int $J$ Spine Surg. 2019;13(6):491-500.

36. Wong $\mathrm{C}, \mathrm{Hu} \mathrm{H}$, Hsieh M, Huang K. Optimization of three-level cervical hybrid surgery to prevent adjacent segment disease: a finite element study. Front Bioeng Biotechnol. 2020;8:154. doi:10.3389/fbioe.2020.00154

37. Lee JC, Lee SH, Peters C, Riew KD. Risk-factor analysis of adjacent-segment pathology requiring surgery following anterior, posterior, fusion, and nonfusion cervical spine operations: survivorship analysis of 1358 patients. J Bone Joint Surg Am. 2014;96(21):1761-1767. doi:10.2106/JBJS.M.01482

38. Kong L, Cao J, Wang L, Shen Y. Prevalence of adjacent segment disease following cervical spine surgery: a PRISMAcompliant systematic review and meta-analysis. Medicine (Baltimore). 2016;95(27):e4171. doi:10.1097/MD.0000000000004171

39. Alhashash M, Shousha M, Boehm H. Adjacent segment disease after cervical spine fusion: evaluation of a 70 patient long-term follow-Up. Spine (Phila Pa 1976). 2018;43(9):605609. doi:10.1097/BRS.0000000000002377

40. Xu S, Liang Y, Zhu Z, Qian Y, Liu H. Adjacent segment degeneration or disease after cervical total disc replacement: a meta-analysis of randomized controlled trials. J Orthop Surg Res. 2018;13(1):244. doi:10.1186/s13018-018-0940-9

41. Barbagallo GMV, Assietti R, Corbino L, et al. Early results and review of the literature of a novel hybrid surgical 
technique combining cervical arthrodesis and disc arthroplasty for treating multilevel degenerative disc disease: opposite or complementary techniques? Eur Spine J. 2009;18(Suppl 1):2939.

42. Ji GY, Oh $\mathrm{CH}$, Shin DA, et al. Artificial disk replacement combined with fusion versus 2-level fusion in cervical 2-level disk disease with a 5-year follow-up. Clin Spine Surg. 2017;30(5):E620-E627.

43. Dong L, Wang D, Chen X, et al. A comprehensive meta-analysis of the adjacent segment parameters in cervical disk arthroplasty versus anterior cervical discectomy and fusion. Clin Spine Surg. 2018;31(4):162-173. doi:10.1097/ BSD.0000000000000552

44. Jia Z, Mo Z, Ding F, He Q, Fan Y, Ruan D. Hybrid surgery for multilevel cervical degenerative disc diseases: a systematic review of biomechanical and clinical evidence. Eur Spine J. 2014;23(8):1619-1632.

45. Lee S, Cho K, Ph D, Kim J, Yoo D, Lee T. Hybrid surgery of multilevel cervical degenerative disc disease: review of literature and clinical results. J Korean Neurosurg Soc. 2012;52(5):452-458.

46. Zhang J, Meng F, Ding Y, et al. Hybrid surgery versus anterior cervical discectomy and fusion in multilevel cervical disc diseases. Medicine (Baltimore). 2016;95(21):e3621.

47. Ji GY, Oh CH, Shin DA, et al. Artificial disk replacement combined with fusion versus 2-level fusion in cervical 2-level disk disease with a 5-year follow-up. Clin Spine Surg. 2017;30(5):E620-E627.

48. Shin DA, Yi S, Yoon DH, Kim KN, Shin HC. Artificial disc replacement combined with fusion versus two-level fusion in cervical two-level disc disease. Spine (Phila Pa 1976). 2009;34(11):1153-1159.

49. Weishaupt D, Zanett M, Boos N, Hodler J. MR imaging and CT in osteoarthritis of the lumbar facet joints. Skeletal Radiol. 1999;28(4):215-219.

50. Smith GW, Robinson RA. The treatment of certain cervical spine disorders by anterior removal of the intervertebral disc and interbody fusion. J Bone Joint Surg Am. 1958;40A(3):607-623.

51. Carreon LY, Glassman SD, Campbell MJ, Anderson PA. Neck Disability Index, short form-36 physical component summary, and pain scales for neck and arm pain: the minimum clinically important difference and substantial clinical benefit after cervical spine fusion. Spine J. 2010;10(6):469-474.

52. Parker SL, Godil SS, Shau DN, Mendenhall SK, McGirt MJ. Assessment of the minimum clinically important difference in pain, disability, and quality of life after anterior cervical discectomy and fusion: clinical article. J Neurosurg Spine. 2013;18(2):154-160.

53. Jonas R, Demmelmaier R, Hacker SP, Wilke HJ.
Comparison of three-dimensional helical axes of the cervical spine between in vitro and in vivo testing. Spine $J$. 2018;18(3):515-524.

54. Patwardhan AG, Carandang G, Voronov LI, et al. Are collapsed cervical discs amenable to total disc arthroplasty? Analysis of prospective clinical data with 2-year follow up. Spine. 2016;41(24):1866-1875.

55. Shi JS, Lin B, Xue C, Zhang HS, Chen ZD, Zhao ZS. Clinical and radiological outcomes following hybrid surgery in the treatment of multi-level cervical spondylosis: over a 2-year follow-up. J Orthop Surg Res. 2015;10(1):185.

56. Buttermann GR. Prospective nonrandomized comparison of an allograft with bone morphogenic protein versus an iliac-crest autograft in anterior cervical discectomy and fusion. Spine J. 2008;8(3):426-435.

57. Martin AR, De Leener B, Cohen-Adad J, et al. Can microstructural MRI detect subclinical tissue injury in subjects with asymptomatic cervical spinal cord compression? A prospective cohort study. BMJ Open. 2018;8(4):e019809. doi:10.1136/bmjopen-2017-019809

58. Wu TK, Wang BY, Meng Y, et al. Multilevel cervical disc replacement versus multilevel anterior discectomy and fusion. Medicine (Baltimore). 2017;96(16):e6503.

59. Buttermann GR. Similar outcomes of hybrid TDR/ ACDF versus multi-level ACDF at 5 year follow-up. Paper presented at: 44th Annual Meeting of the Cervical Spine Research Society, Toronto, CA, Dec 1-3, 2016.

60. Passias PG, Bortz CA, Segreto FA, et al. Development of a modified cervical deformity frailty index: a streamlined clinical tool for preoperative risk stratification. Spine (Phila Pa 1976). 2019;44(3):169-176. doi:10.1097/BRS.0000000000002778

Disclosures and COI: This study did not receive any funding or external support.

Corresponding Author: Matthew ScottYoung, MBBS, Gold Coast Spine, 27 Garden Street, Southport, Gold Coast, Australia, 4215. Phone: +617 5528 6477; Fax: +617 5503 1933; Email: swalter@goldcoastspine.com.au.

Published 30 September 2020

This manuscript is generously published free of charge by ISASS, the International Society for the Advancement of Spine Surgery. Copyright @ 2020 ISASS. To see more or order reprints or permissions, see http://ijssurgery.com. 